Original Article

\title{
ORAL DIURETIC ACTIVITY OF HOT WATER EXTRACT OF H-GRADE QUILLS OF CINNAMOMUM ZEYLANICUM BLUME IN RATS
}

\author{
GIHANI JAYAWEERA ${ }^{1 *}$, THAMASI MAKULOLUWA ${ }^{2}$, KAMAL PERERA ${ }^{3}$, JEEVA K. AMARARATNE ${ }^{4}$, SIRIMAL \\ PREMAKUMARA ${ }^{5}$, DAYA RATNASOORIYA ${ }^{6}$
}

1,6Department of Basic Sciences, Faculty of Allied Health Sciences, General Sir John Kotelawela Defence University, Sri Lanka, ${ }^{2}$ Department of Clinical Sciences, Faculty of Medicine, General Sir John Kotelawela Defence University, Sri Lanka, ${ }^{3}$ Faculty of Medicine, General Sir John Kotelawela Defence University, Sri Lanka, ${ }^{4}$ Bestcare Animal Hospital, Nugegoda, Sri Lanka, 5 Industrial Technology Institute, Sri Lanka Email: gihanijayaweera@kdu.ac.lk

Received: 08 Feb 2018 Revised and Accepted: 07 Sep 2018

ABSTRACT

Objective: Cinnamomum zeylanicum Blume is claimed in Sri Lankan traditional medicine as a diuretic. Diuretics that are in current use possess serious adverse effects. Thus, there is a need for discovering efficacious and safe diuretics possibly from natural sources. Hence, the study was carried out to scientifically evaluate the diuretic potential of Cinnamomum zeylanicum Blume in vivo.

Methods: Wistar albino rats weighing 180-270 g of either sex were divided into five groups containing six subjects in each. All were starved for $18 \mathrm{~h}$ and hydrated subsequently with oral sodium chloride solution (0.9\%). Group, I (control) received normal saline (15 ml per animal orally). Group II, III, and IV received different doses (1500, 2250, $3000 \mathrm{mg} / \mathrm{kg}$ ) of freeze-dried hot water extract of Cinnamomum zeylanicum Blume orally. Group V; (standard) received furosemide $(13 \mathrm{mg} / \mathrm{kg})$. Rats were placed individually in metabolic cages. Cumulative urine outputs at hourly intervals for six hours, urinary $\mathrm{Na}^{+}, \mathrm{K}^{+}, \mathrm{Cl}^{-}, \mathrm{HCO}_{3}{ }^{-}$, specific gravity, $\mathrm{pH}$ and total dissolved solids were determined.

Results: A strong dose-dependent diuretic activity with a rapid onset of action, rapid peak diuresis and short duration of action was observed compared to furosemide. The diuretic action was accompanied with a significant $(\mathrm{p}<0.05)$ increase in urinary $\mathrm{Na}^{+}, \mathrm{HCO}_{3}{ }^{-}$and $\mathrm{pH}$ and decrease in urinary $\mathrm{H}^{+}$.

Conclusion: The results indicated that hot water extract of Cinnamomum zeylanicum Blume possesses marked diuretic action compared to furosemide. This is mediated primarily via loop diuretic mechanism similar to furosemide and partly by carbonic anhydrase inhibitory action.

Keywords: Cinnamon, Cinnamomum zeylanicum, Water extract, Diuretic, Urine output, Loop diuretic, Thiazide diuretic

C) 2018 The Authors. Published by Innovare Academic Sciences Pvt Ltd. This is an open-access article under the CC BY license (http://creativecommons.org/licenses/by/4.0/) DOI: http://dx.doi.org/10.22159/ijpps.2018v10i10.25200

\section{INTRODUCTION}

Cinnamomum zeylanicum Blume is a popular spice endemic to Sri Lanka and southern parts of India [1]. "Ceylon cinnamon" and "true cinnamon" are the terms commonly used to refer Cinnamomum zeylanicum Blume [2]. In native Sri Lankan language, it is termed as "kurundu". It belongs to the genus Cinnamomum of the plant family Lauraceae. Ceylon cinnamon compared to other varieties (Indonesian, Vietnamese and Chinese) is softer, lighter in colour and rolled into layers [3]. It has a delicate taste and unique aroma and an ultra-low level of coumarin, a known anticoagulant [3]. Therefore, from the ancient to modern times the trade value of Ceylon cinnamon remains high. This ancient spice is now granted GRAS (Generally recognized as safe) by the United States food and drug administration [4].

Traditionally in many cultures, it has been used as a spice and a flavoring agent. Some nations used it as an odorant [5]. Apart from its culinary use, it has been used as a remedy in traditional systems of medicine in treating respiratory, digestive and gynecological ailments $[2,6,7,8]$. Cinnamon is still a popular spice in the savoury dishes and bakery products [7]. Cinnamon essence is highly demanded in the perfume industry. Recently, there is increased popularity for cinnamon tea. Even in the modern era native physicians and herbalists continue to use it as a herbal remedy [6].

Every part of the cinnamon tree (stem, root, leaves, flower, and fruit) has a medicinal or culinary value [2]. When the inner bark of the tree is dried, it is folded into a tubular form known as cinnamon quill/stick [9]. Cinnamon quills are graded based on ISO 6535:1997 and SLS 81:2000 standards by the Sri Lanka spice council into four main grades. Those are Alba, continental (C), Mexican (M) and Hamburg $(\mathrm{H})$ grades. The latter, the market grade consists of rough barks of good quality cinnamon. The main constituents of the essential oils of the cinnamon bark are trans-cinnamaldehyde, eugenol, and linalool which account for $82.5 \%$ of the total composition [2].

In vitro and in vivo studies in animals and humans have demonstrated many beneficial health effects of Cinnamomum zeylanicum. Those are antimicrobial [10], antifungal [11], antiparasitic [12], anti-lipidemic [5], anti-diabetes [13] anticancer [11], anti-Alzheimer [14], anti-gastric ulcer [5], antioxidant and anti-inflammatory effects [15]. There are claims in Sri Lankan indigenous medicine that cinnamon possesses diuretic activity [16]. But this is not yet scientifically proven.

The drugs that are used to enhance the urine volume are termed diuretics [17]. Those are widely used clinically to treat conditions such as peripheral or pulmonary oedema, congestive heart failure, cirrhosis, kidney diseases, renal failure, hypertension, glaucoma and nephrolithiasis $[17,18,19,26]$. Though the currently using diuretics are efficacious, they have adverse effects such as volume depletion, hypokalemia and metabolic disturbances [20]

Therefore, there is a timely need of discovering efficacious relatively cheap novel diuretics with less adverse effects possibly from natural sources. Accordingly, this systematic study was carried out to evaluate the diuretic activity and possible mode of action(s) of water extract of the stem bark of Cinnamomum zeylanicum in rats.

\section{MATERIALS AND METHODS}

Experimental animals

Healthy adult Wistar rats of either sex (180-270 g) obtained from the medical research institute, Colombo, Sri Lanka were used in the study. These animals were housed in the animal house of General Sir John Kotelawela defense university under standardized conditions (temperature: $28-31{ }^{\circ} \mathrm{C}$, photoperiod: approximately $12 \mathrm{~h}$ of natural light per day, relative humidity: 50-55\%). All the animals were 
acclimatized for $14 \mathrm{~d}$ before using for the experiment. The animals were provided with pelleted food (Master feed limited, Colombo, Sri Lanka) and domestic tap water ad-libitum. The experiments were conducted in accordance with the internationally accepted laboratory animal use and care guidelines (EEC Directive of 1986; 86/609/EEC) [21]. The study was approved by the ethical review committee of the Institute of Biology, Sri Lanka. (Approval No: ERC IOBSL 13007 15).

\section{H-grade quills of Cinnamomum zeylanicum blume}

$\mathrm{H}$ grade quills of Cinnamomum zeylanicum Blume (HCZ) was purchased from local market. The organoleptic properties of the quills were assessed by the professional experts in herbal technology Section of industrial technology institute, Colombo, Sri Lanka. (Specimen No: HTS-CIN-GJ1).

\section{Chemicals and reagents}

Furosemide (State Pharmaceutical Cooperation, Colombo, Sri Lanka) was used as the reference drug. Electrode fill solutions for $\mathrm{Na}^{+}, \mathrm{Cl}$ and $\mathrm{pH}$ (FINELEMC0006), for $\mathrm{K}^{+}$(FINELEMC0005) and reference electrode fill solution (FINELEMC0009) from ERBA diagnostics mannheim $\mathrm{GmbH}$, Germany were used in the analysis of urinary electrolytes. Reagent kits for quantitative determination of alanine aminotransferase activity/ALT (E. C.2.6.1.2), aspartate transferase activity/AST (E. C.2.6.1.1) and creatinine (REF 80107) from Biolabo reagents, Maizy, France were used.

\section{Preparation of the hot water extract}

One kilogram ( $1 \mathrm{~kg}$ ) of HCZ was crushed in a ball mill to get $2-3 \mathrm{~cm}$ sized cinnamon pieces. Then it was boiled for $4 \mathrm{~h}$ with $6 \mathrm{l}$ of water (1:6 ratio) under reflux conditions. Subsequently, water was removed, and the remainder was boiled for the second time with the same amount of water for $2 \mathrm{~h}$. The two water fractions were combined and freeze-dried (Christ-Alpha 1-4 Freeze dryer, Biotech International, Germany) for $3 \mathrm{~d}$ at $-60{ }^{\circ} \mathrm{C} .1500,2250$ and $3000 \mathrm{mg} / \mathrm{kg}$ doses were made in $3 \mathrm{ml}$ water for oral administration.

\section{Evaluation of diuretic activity}

Diuretic activity was assessed as described previously [22]. Briefly, fiftyfour (54) rats were starved for $18 \mathrm{~h}$, and their urinary bladders were emptied by gentle compression of the pelvic area and pull off the tails. Each of these rats was then orally administered with $15 \mathrm{ml}$ of isotonic saline to achieve an equal hydration status. One hour later, they were randomly divided in to six groups and treated in the following manner; Group $1(\mathrm{~N}=18): 3 \mathrm{ml}$ of isotonic saline, Group $2(\mathrm{~N}=6): 1500 \mathrm{mg} / \mathrm{kg}$ dose of HCZ, Group $3(\mathrm{~N}=6)$ : $2250 \mathrm{mg} / \mathrm{kg}$ dose of HCZ, Group $4(\mathrm{~N}=6)$ : $3000 \mathrm{mg} / \mathrm{kg}$ dose of HCZ, Group 5 ( $\mathrm{N=18):} 13 \mathrm{mg} / \mathrm{kg}$ of furosemide, the reference drug (State Pharmaceutical Cooperation, Colombo, Sri Lanka). Each rat was individually placed in metabolic cages. Urine was collected in graduated cylinders. The cumulative urine output of each rat was determined at hourly intervals for six hours. During this period, the rats had no access to food or water. At the end of $6 \mathrm{~h}$ urine volumes were recorded and urine outputs were calculated in relation to body weight and expressed as $\mathrm{ml} / 100 \mathrm{~g}$ body weight.

\section{Assessment of diuretic indices}

Percentage of saline load excreted (volume of urine/volume of saline load $\times 100$ ), percentage of urinary excretion (total urinary output/ total liquid administered $\times 100$ ), diuretic action (urinary output of treated group/urinary output of control group) and diuretic activity (diuretic action of test extract/diuretic action of standard drug) were calculated [23].

\section{Evaluation of electrolyte excretion in urine}

Ten (10) rats were randomly divided into two equal groups $(\mathrm{N}=5)$, starved and hydrated as described previously. One group was orally administered with $3 \mathrm{ml}$ of isotonic saline while the other group was orally administered with $2250 \mathrm{mg} / \mathrm{kg}$ dose of HCZ. They were individually placed in metabolic cages, and urine was collected in graduated cylinders. Their cumulative urine output after $6 \mathrm{~h}$ was measured. Urine parameters such as colour, turbidity, $\mathrm{pH}$, glucose, specific gravity, protein, bilirubin, urobilinogen, ketone, nitrite, traces of blood and leucocytes were determined using the reagent strips (URIPATH, Plasmatec Lab Healthcare Ltd, UK). Estimation of electrolytes was performed: urinary $\mathrm{Na}^{+}, \mathrm{K}^{+}$and $\mathrm{Cl}^{-}$were measured in $\mathrm{mmol} / \mathrm{l}$ and $\mathrm{pH}$ by direct measurement by an ion selective electrodes ("Ebra Lyte Analyzers", EBRA Diagnostics Mannheim $\mathrm{GmbH}$, Mannheim, Germany) and urinary $\mathrm{HCO}_{3}{ }^{-}$level were measured titrimetrically. $\mathrm{H}^{+}$concentration in $\mathrm{mmol} / \mathrm{l}$ was computed from $\mathrm{pH}$ values using a standard $\mathrm{pH}$ table. Urinary total dissolved solids (TDS) were measured using a refractometer.

\section{Assessment of diuretic indices}

Using the data obtained for electrolytes following diuretic indices were computed: Saliuretic indices for $\mathrm{Na}^{+}, \mathrm{K}^{+}$and $\mathrm{Cl} ;$ Aldosterone secretion index $\left(\mathrm{Na}^{+} / \mathrm{K}^{+}\right)$; Thiazide diuretic index $\left(\mathrm{Na}^{+} / \mathrm{Cl}-\right)$, Carbonic anhydrase inhibition index $\left[\mathrm{Cl} /\left(\mathrm{Na}^{+}+\mathrm{K}^{+}\right)\right]$, Intra and extracellular $\mathrm{pH}$ regulatory index $\left(\mathrm{HCO}_{3}-\mathrm{H}^{+}\right)$and urine alkali index $\left(\mathrm{Na}^{+} / \mathrm{H}^{+}\right)[23]$.

\section{Assessment of toxicity effects}

Ten (10) male and female rats were randomly divided into two equal groups ( $\mathrm{N}=5$ /group). One group was orally administered with $3 \mathrm{ml}$ of isotonic saline while another group was orally administered daily (at $0900 \mathrm{~h}$ ) with $2250 \mathrm{mg} / \mathrm{kg}$ dose of HCZ for ten consecutive days. On day 0 (pre-treatment) and day 11th post-treatment, the rats were anaesthetized with anaesthetic ether, and blood samples (1-1.5 ml) were collected aseptically from the tail vein from each rat. During this period, rats were observed twice daily closely for overt signs of toxicity (salivation, lacrimation, breathing distress, ptosis, stupor, squint, teeth exposure, writhing, convulsions, tremors, yellowing of fur, loss of fur, vaginal bleeding), stress (erection of fur and exophthalmia), behavioural abnormalities (impairment of spontaneous movements, climbing, cleaning of face, ataxia, rolling and other postural changes), aversive behaviours (biting and scratching, licking of tails, paw and penis, intense grooming or vocalization) or diarrhoea [23].

Estimation of aspartate transaminase (AST) and alanine transaminase (ALT) (to evaluate liver toxicity), blood urea and creatinine levels (to evaluate kidney toxicity) were made using respective standard reagent kits (Biolabo Reagents, Maizy, France) as per the manufacturer's instructions given.

\section{Statistical analysis}

Data are given as means+standard error of the mean (SEM). Statistical comparisons are made as appropriate using KruskallWallis and Mann Whitney U-test using SPSS version 16 statistical package. The significance level was set at $\mathrm{P}<0.05$.

\section{RESULTS}

\section{Evaluation of diuretic activity}

All three doses of HCZ exhibited a comparatively high diuretic action and diuretic activity as depicted in table I. When compared with furosemide, the diuretic potency of the two doses (2250 and $3000 \mathrm{mg} / \mathrm{kg}$ ) HCZ was approximately $23 \%$ less in terms of diuretic activity index.

Table 1: Effect of HCZ on cumulative urine output and some selected diuretic indices

\begin{tabular}{|c|c|c|c|c|c|c|}
\hline Groups & $\begin{array}{l}\text { CUO } \\
(\mathrm{ml} / 100 \mathrm{~g} \mathrm{bw})\end{array}$ & $\begin{array}{l}\% \text { increase in } \\
\text { CUO }\end{array}$ & $\begin{array}{l}\text { \% Saline } \\
\text { excreted }\end{array}$ & $\begin{array}{l}\text { \% Urine } \\
\text { excretion }\end{array}$ & $\begin{array}{l}\text { Diuretic } \\
\text { action }\end{array}$ & $\begin{array}{l}\text { Diuretic } \\
\text { activity }\end{array}$ \\
\hline $\begin{array}{l}\text { Control }(0.9 \% \text { Normal saline } 3 \\
\text { ml orally }(n=18)\end{array}$ & $0.89 \pm 0.16$ & - & $13.24 \pm 2.56$ & $9.14 \pm 1.72$ & - & - \\
\hline $1500 \mathrm{mg} / \mathrm{kg}$ dose of HCZ $(\mathrm{n}=6)$ & $1.52 \pm 0.27$ & 69.46 & $23.70 \pm 5.93$ & $15.83 \pm 3.61$ & 1.69 & 0.61 \\
\hline $2250 \mathrm{mg} / \mathrm{kg}$ dose of HCZ $(\mathrm{n}=6)$ & $1.91 * \pm 0.24$ & 112.85 & $25.99 * \pm 2.98$ & $18.37 * \pm 2.14$ & 2.13 & 0.76 \\
\hline $3000 \mathrm{mg} / \mathrm{kg}$ dose of HCZ $(\mathrm{n}=6)$ & $1.92 * \pm 0.11$ & 114.53 & $28.14^{*} \pm 2.06$ & $19.46^{*} \pm 1.32$ & 2.15 & 0.77 \\
\hline $\begin{array}{l}\text { Standard Frusemide } 13 \mathrm{mg} / \mathrm{kg} \\
\text { orally }(\mathrm{n}=18)\end{array}$ & $2.50 \pm 0.18$ & 179.14 & $34.64 \pm 2.47$ & $24.42 \pm 1.69$ & 2.79 & 1.00 \\
\hline
\end{tabular}

CUO is in mean+SEM, Compared to control by Kruskall-Wallis and Mann Whitney U-tests, bw-body weight, *P<0.05: Significant, CUO-cumulative urine output for $6 \mathrm{~h}$, SEM: standard error of mean 
As shown in fig. 1, the onset of diuretic activity of HCZ was very rapid (within $1 \mathrm{~h}$ ) and so was the time for peak diuresis (1-2 h). The duration of the diuretic action of HCZ was short (up to $2 \mathrm{~h}$ ) whilst it was about $3 \mathrm{~h}$ for Furosemide.

\section{Electrolyte excretion in urine}

As shown in the table 2 diuresis induced by HCZ was accompanied with electrolyte excretion.

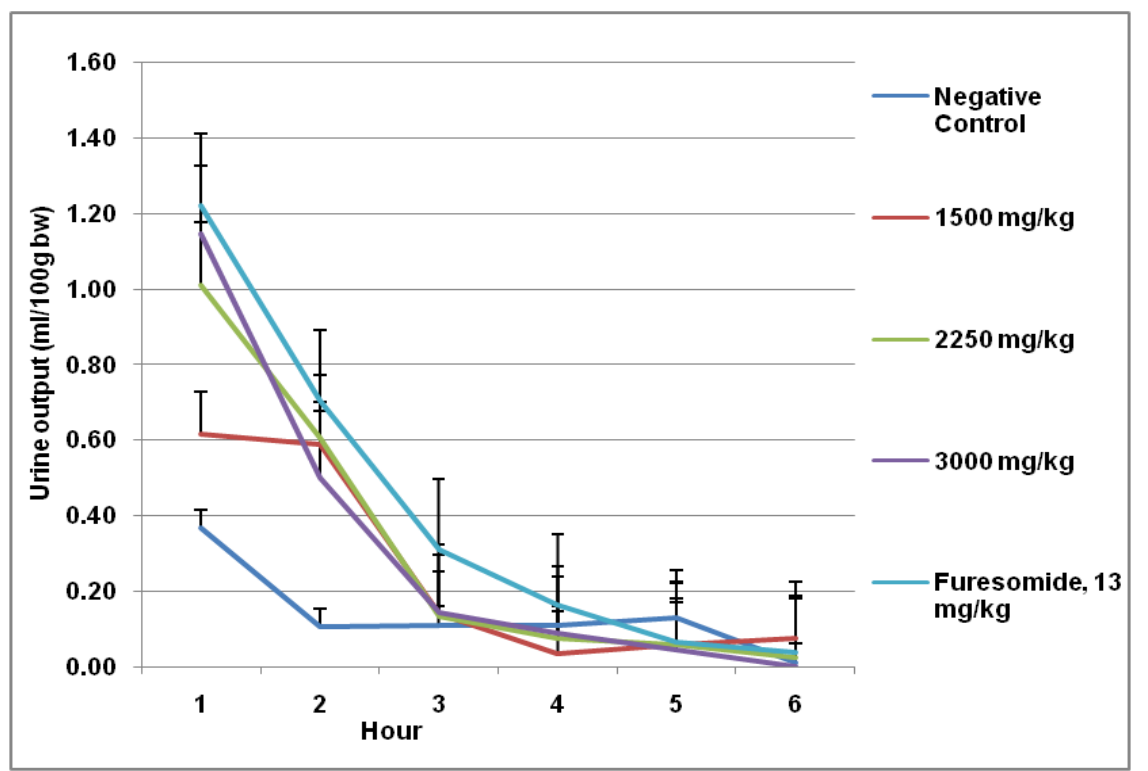

Fig. 1: Hourly urine outputs for $6 \mathrm{~h}$ of rats orally administered with hot water extract of Cinnamomum zeylanicum (Mean+SEM)

Table 2: Effects of oral administration of hot water extract of Cinnamomum zeylanicum on urine electrolytes excretion of rats

\begin{tabular}{|c|c|c|c|c|c|c|c|c|}
\hline & $\mathrm{Na}^{+}(\mathrm{mmol} / \mathrm{l})$ & $\mathrm{K}^{+}(\mathrm{mmol} / \mathrm{l})$ & $\mathrm{Cl}^{-}(\mathrm{mmol} / \mathrm{l})$ & $\begin{array}{l}\mathrm{HCO}_{3} \\
(\mathrm{mmol} / \mathrm{l}) \\
\times 10^{-6} \\
\end{array}$ & $\mathrm{H}^{+}(\mathrm{mmol} / \mathrm{l}) \times 10^{-5}$ & $\mathrm{Na}^{+} \mathrm{SI}$ & $\mathbf{K}^{+} \mathbf{S I}$ & Cl-SI \\
\hline Control Group & $117.425 \pm 6.755$ & $108.605 \pm 52.775$ & $210.850 \pm 62.589$ & $1.300 \pm 0.147$ & $1.148 \pm 0.009$ & 1.00 & 1.00 & 1.00 \\
\hline Treated Group & $217.780 * \pm 17.898$ & $125.302 \pm 9.822$ & $297.760 \pm 21.271$ & $2.240 * \pm 0.269$ & $1.023^{*} \pm 0.001$ & 1.85 & 1.15 & 1.41 \\
\hline
\end{tabular}

Observations are in mean+SEM, Compared to control by Kruskall-Wallis and Mann Whitney U-tests, bw-body weight, $* \mathrm{P}<0.05$ : Significant, SI: saliuretic index, SEM: standard error of mean

Other diuretic indices

Table 3: Effects of oral administration of hot water extract of Cinnamomum zeylanicum on some other urine indices of rats

\begin{tabular}{llllc}
\hline & ASI & TDI & CAII & PRI \\
\hline Control Group & $1.785 \pm 1.115$ & $0.852 \pm 0.345$ & $0.523 \pm 0.159$ & $0.113 \pm 0.026$ \\
Treated Group & $1.757 \pm 0.134$ & $0.730 \pm 0.016$ & $0.578 \pm 0.006$ & $0.662^{*} \pm 0.472$ \\
\hline
\end{tabular}

Observations are in mean+SEM, Compared to control by Kruskall-Wallis and Mann Whitney U-tests, bw-body weight, $*$ P $<0.05$ : Significant, ASI: aldosterone secretion index, TDI-thiazide diuretic index, CAII-carbonic anhydrase inhibition index, PRI-intra, and extracellular pH regulatory index, UAI-urinary alkali index, SEM: standard error of mean

Urine macroscopic appearance, urine strip test and other parameters

Macroscopically, urine samples of both groups were clear and pale yellow. Urobilinogen, glucose, bilirubin, ketones, blood, protein, nitrite and leukocytes were negative in the urine samples of both groups.

\section{Assessment of toxicity effects}

All animals survived during the ten consecutive days without exhibiting any overt signs of toxicity.

Table 3: Effects of oral administration of hot water extract of Cinnamomum zeylanicum on urinary TDS, pH, and SG

\begin{tabular}{llll}
\hline & TDS (mg/l) & pH & \multicolumn{1}{c}{ SG } \\
\hline Control Group & $7.160+0.001$ & $7.463+0.123$ & $1.022+0.001$ \\
Treated Group & $5.060+0.303$ & $7.892 *+0.070$ & $1.023+0.001$ \\
\hline
\end{tabular}

Observations are in mean+SEM, Compared to control by Kruskall-Wallis and Mann Whitney U-tests, bw-body weight, ${ }^{*} \mathrm{P}<0.05$ : Significant, TDS: total dissolved solids, SG-specific gravity, SEM: standard error of mean 
Table 4: Effects of oral administration of hot water extract of Cinnamomum zeylanicum on liver and kidney function

\begin{tabular}{llll}
\hline & ALT IU/l & AST IU/l & Blood urea mg/dl \\
\hline Control Group & $209.49 \pm 59.33$ & $246.19 \pm 103.12$ & $24.89 \pm 5.53$ \\
Treated Group & $172.84 \pm 25.27$ & $204.19 \pm 36.55$ & $24.86 \pm 2.46$ \\
\hline
\end{tabular}

Observations are in mean+SEM, Compared to control by Kruskall-Wallis and Mann Whitney U-tests, bw-body weight, ${ }^{*} \mathrm{P}<0.05$ : Significant, ALT: alanine aminotransferase, AST: aspartate aminotransferase, IU: international units, SEM: standard error of mean

\section{DISCUSSION}

This study for the first time evaluated the oral diuretic potential of hot water extract of the dried barks of HCZ in conscious rats. The bioassay; hydrated diuretic model is widely used, validated, a reliable and sensitive technique in assessing the diuretic potential of pharmacophores. The authenticated cinnamon samples used were fresh, pure, and are of high quality.

The results conclusively showed that the hot water extract of HCZ possesses potent and dose-dependent diuretic activity in terms of cumulative urine output, diuretic activity, diuretic action index, percentage saline excretion, and percentage urinary excretion. The diuretic action exerted was acute and marked when compared to furosemide. Since it is accompanied with marked natriuresis (in terms of urinary $\mathrm{Na}^{+}$level and $\mathrm{Na}^{+}$saliuretic index), it was a true oral diuretic activity. Dose dependency of the cinnamon induced diuretic action suggests that the effect is genuine, intrinsic and causal which has not resulted from nonspecific actions. This is an important and interesting finding for a spice which is widely used as an authentic Sri Lankan cuisine.

The extremely prompt onset of action and equally rapid peak diuresis time indicate that the phytoconstituents which exert the diuretic action are rapidly absorbed in the gastrointestinal tract, and the diuresis is unlikely to be mediated via a secondary metabolite/s. The short duration of action suggests rapid metabolism and/or fast clearance of the active constituent/s as reported with some herbal diuretics [22]. Such an action profile is desirable with some forms of diuretic therapy.

It is now known that several herbs used as diuretics on traditional and folk medicines are indeed aquaritics [22]. An "aquaretic" is an agent that increases urinary output without promoting electrolyte loss [22]. Since the diuretic action of HCZ was accompanied by marked natriuresis, moderate chlorouresis and mild kaliuresis it is unlikely to function as an aquaretic. Herbs with high salt contents are known to induce diuresis [23]. However, Cinnamomum zeylanicum has not been shown to contain high salt. Therefore, it is unlikely that it triggers the observed diuretic action via such a nonspecific mechanism. Some herbal diuretics are known to stimulate the hypothalamic thirst center thereby increase the fluid intake leading to increased urine output [23]. However, such a mode of action is also unlikely to operate in this study as the rats had no access to water during the 6-hour experimental period.

The presence of large quantities of osmotically active ions in the renal tubular filtrate promotes osmotic diuresis by decreasing water reabsorption from aquaporin channels [24]. The specific gravity (SG) and total dissolved solids (TDS) are considered indirect measures of urine ionic content. As those are not significantly altered in the urine of cinnamon treated rats the observed diuretic action cannot be attributed due to an osmotic mechanism. Further evidence to this notion is that up to now no orally active osmotic diuretic (either synthetic or herbal) is known. Antidiuretic hormone (ADH) antagonist promotes diuresis resulting in polyuria and low urine osmolality [25]. Such a mode of action is, however, unlikely in the present study as there was no significant change in the SG and TDS in the urine of cinnamon extract treated rats. The all known osmotic diuretics and $\mathrm{ADH}$ antagonists are only intravenously active [22].

Potassium-sparing diuretics act by inhibiting aldosterone sensitive epithelial sodium channels (ENaCs) in the late distal tubule and collecting duct [24]. The parameters such as $\mathrm{K}^{+}$content, $\mathrm{K}^{+}$saluretic index, and aldosterone secretory index (urinary $\mathrm{Na}^{+} / \mathrm{K}^{+}$ratio) of urine of treated rats was not significantly altered. Therefore, the diuretic action provoked by cinnamon extract cannot be attributed to a potassium-sparing diuretic effect. Thiazide diuretics inhibit $\mathrm{Na}^{+} / \mathrm{Cl}^{-}$symporters [24]. The observation of unaltered thiazide diuretic index and urinary alkali index suggest that diuretic action of cinnamon extract is not mediated via a thiazide-like mode of action although it produces marked natriuresis.

Loop diuretics such as furosemide induce diuresis by inhibiting the $\mathrm{Na}^{+} / \mathrm{K}^{+} / \mathrm{Cl}$ cotransporter in the thick region of the ascending limb of the loop Henley of nephrons [24]. In contrast, cinnamon extract as mentioned earlier, provoked strong extremely rapid and short lasting diuresis almost having features of a loop diuretic, furosemide. Further, diuresis was accompanied with marked natriuresis, moderate chlorouresis, and extremely low kaliuresis. Collectively, these observations suggest furosemide like a loop diuretic action.

Carbonic anhydrase inhibitors inhibit the reaction between water and carbon dioxide that generate $\mathrm{H}^{+}$and $\mathrm{HCO}_{3}$ - decreasing the availability of $\mathrm{H}^{+}$for $\mathrm{Na}^{+} / \mathrm{H}^{+}$exchanger in the proximal convoluted tubule. Then $\mathrm{Na}^{+}$is reduced, luminal $\mathrm{HCO}_{3}{ }^{-}$neutralization is impaired and $\mathrm{Cl}^{-}$reabsorption is increased resulting alkaline diuresis [24]. In the urine of cinnamon treated rats, urinary $\mathrm{HCO}_{3}-$ (by $72 \%$ ) level and urinary $\mathrm{pH}$ (by $6 \%$ ) were significantly increased, and the urinary $\mathrm{H}^{+}$ level (by 20\%) significantly decreased. Further, intra and extracellular pH regulatory index was significantly increased (by 488\%). This is indicative of carbonic anhydrase inhibiting activity. Surprisingly, however, carbonic anhydrase inhibition index was only slightly (by $11 \%$ ) but insignificantly increased in spite of high natriuresis and moderately high chlorouresis. This may be due to the low kaliuresis. Thus, carbonic anhydrase inhibition activity is also likely to contribute, at least partly, to the diuretic action of cinnamon extract.

Interestingly, subchronic administration of high dose of cinnamon extract produced no mortality, morbidity or overt signs of toxicity, renotoxicity (in terms of serum urea and creatinine level) or hepatotoxicity (in terms of ALT and AST levels) indicating its safety with oral administration.

\section{CONCLUSION}

This study shows for the first time, safe and orally active strong diuretic activity in hot water extract of $\mathrm{H}$ grade quills of Sri Lankan Cinnamomum zeylanicum Blume. Diuretic action is mediated primarily via loop diuretic action and minor carbonic anhydrase inhibition activity. Further, the results experimentally justify the claim made by Sri Lankan traditional medicine, and Ayurvedic medicine Cinnamomum zeylanicum Blume possess diuretic activity.

\section{ACKNOWLEDGMENT}

This research was funded by the research grants for probationary lecturers by General Sir John Kotelawala Defence University, Sri Lanka (KDU/DVC/AC/86). Thanks also due to Ms W. P. K. M. Abeysekara of industrial technology institute, Mr B. D. I. Madhushan of General Sir John Kotelawala Defence University and Dr D Karunarathna of Bestcare animal hospital for the technical support.

\section{AUTHORS CONTRIBUTIONS}

Gihani Jayaweera, Thamasi Makuloluwa, and Daya Ratnasooriya conceptualized the experiment. Gihani Jayaweera, Kamal Perera, and Jeeva K Amararatne carried out the work. Sirimal Premakumara contributed to the sample preparation. Gihani Jayaweera processed 
the experimental data, performed the data analysis and drafted the manuscript with inputs from all the authors. Daya Ratnasooriya supervised the work, guided the data analysis and edited the manuscript.

\section{CONFLICTS OF INTERESTS}

All authors have none to declare

\section{REFERENCES}

1. Anonymous. WHO monographs on selected medicinal plants. Geneva (SZ). World Health Organization; 1999.

2. Ranasinghe P, Pigera S, Premakumara GS, Galappaththy P, Constantine GR, Katulanda P. Medicinal properties of "true"cinnamon (Cinnamomum zeylanicum): a systematic review. BMC Complement Altern Med 2013;13:275.

3. Kawatra P, Rajagopalan R. Cinnamon: mystic powers of a minute ingredient. Pharmacogn Res 2015;7:1-6.

4. Ziegenfuss T, Hofheins J, Mendel R, Landis J, Anderson R. Effects of a water-soluble cinnamon extract on body composition and features of the metabolic syndrome in prediabetic men and women. J Int Soc Sports Nutr 2006;3:45-53.

5. Rao P, Gan S. Cinnamon: a multifaceted medicinal plant. EvidBased Complement Alt Med 2014:1-12. http://dx.doi.org/ 10.1155/2014/642942.

6. Balijepalli M, Buru A, Sakirolla R, Pichika M. Cinnamomum genus: a review on its biological activities. Int J Pharm Pharm Sci 2017;9:1-11.

7. Maheshwari R, Chauhan A, Gupta A, Sharma S. Cinnamon: an imperative spice for human comfort. Int J Pharm Res Biosci 2013;2:131-45.

8. Monashi D, Suvra M, Budhimanta M, Jayram H. Ethanobotany, phystochemical and pharmacological aspects of Cinnamomum zeylanicum Blume. Int Res J Pharm 2013;4:58-64.

9. Anilakumar K, Naveen J. Cinnamon-a promising spice with nutraceutical properties. World J Pharm Res 2016;5:453-66.

10. Tarranum A, Malhotra U, Ghildiyal A, Chandola P. Antimicrobial activity of plants (Cinnamomum zeylanicum, Cedrus deodara, Eucalyptus globulus, Rosmarinus officinalis) essential oils against some bacterial and fungal strains. Octa J Biosci 2014;2:49-52.

11. Hamidpour $R$, Hamidpour $M$, Hamidpour $S$, Shahlari $M$. Cinnamon from the selection of traditional applications to its novel effects on the inhibition of angiogenesis in cancer cells and prevention of Alzheimer's disease, and a series of functions such as antioxidant, anticholesterol, antidiabetes, antibacterial, antifungal, nematicidal, acaracidal, and repellent activities. J Trad Complem Med 2015;5:66-70.
12. Samarasekera R, Kalhari KS, Weerasinghe IS. The mosquitocidal activity of leaf and bark essential oils of Ceylon Cinnamomum zeylanicum. J Essent Oil Res 2005;17:301-3.

13. Ranasinghe P, Jayawardana R, Galappaththy P, Constantine G, Gunawardana N, Katulanda P. Efficacy and safety of "true" cinnamon (Cinnamomum zeylanicum) as a pharmaceutical agent in diabetes: a systematic review and meta-analysis: efficacy and safety of "true" cinnamon in diabetes. Diabet Med 2012;29:1480-92.

14. Gruenwald J, Freder J, Armbruester N. Cinnamon, and health. Crit Rev Food Sci Nutri 2010;50:822-34.

15. Abeysekera W, Premakumara G, Ratnasooriya WD. In vitro antioxidant properties of leaf and bark extracts of ceylon cinnamon (Cinnamomum zeylanicum Blume). Trop Agric Res 2013;24:128-38.

16. Weragoda PB. Osuthuru visithuru. Colombo (SL): Department of Ayuruveda; 1994.

17. Sayana S, Christina, Medabala T, Patil P. Study of diuretic activity of ethonolic extract of leaves of Cissampelos pareira in rats. Asian J Pharm Clin Res 2014;7:157-9.

18. Maura H, Kumar T. A review on comprehensive overview in the management of nephrotic disorders. J Crit Rev 2016;3:34-43.

19. Mohandas R, Chandrashekar R, Manohar V, Kateel R. Potent and efficacious diuretic activity with the potassium-sparing effect of Terminalia belerica fruit pulp aqueous extract in Wistar albino rats. Asian J Pharm Clin Res 2016;9:241-3.

20. Weinberger M. Diuretics and their side effects. Dilemma in the treatment of hypertension. Hypertension 1998;11:16-20.

21. Anonymous. Guiding principles in the use of animals in toxicology, Council Directives 86/609/EEC of 24 November 1986, Society of Toxicology, Reston, Virginia; 2008. p. 1-4.

22. Abeywickrama KRW, Ratnasooriya WD, Amarakoon AMT. Oral diuretic activity of hot water infusion of Sri Lankan black tea (Camellia sinensis L.) in rats. Pharmacogn Mag 2010;6:271-7.

23. Ratnasooriya WD, Muthunayake TBS, Indeesha EK, Ratnasooriya CDT. Oral diuretic activity of Sri Lankan low grown orange pekoe grade black tea (Camellia sinensis L.) in rats. Int J Bioassays 2013;2:286-93.

24. Wile D. Diuretics: a review. Ann Clin Biochem 2012;49:419-31.

25. Katzung B, Masters S, Trevory A. Basic clinical pharmacology. 12th ed. New Delhi (IND): McGraw-Hill Education; 2012.

26. Bhardwaj S, Balgir P, Goel R. Pharmacogenomics and personalized management of hypertension. J Crit Rev 2015; 2:1-6. 